\title{
INTERFACES ENTRE A PRODUÇÃO DE CONHECIMENTOS AMERÍNDIOS E AS RELAÇÕES DE GÊNERO COM OS GUARANI
}

\author{
$*$ \\ Josiane Abrunhosa da Silva Ulrich \\ Universidade de Santa Cruz do Sul - UNISC - Brasil \\ Ana Luisa Teixeira Menezes \\ Universidade de Santa Cruz do Sul - UNISC - Brasil
}

\section{Resumo}

O projeto "Aprendizagens interculturais com os Guarani e produção de conhecimentos ameríndios para a educação", desenvolvido pela Universidade de Santa Cruz do Sul (Unisc) que reúne professores, estudantes de pós-graduação e graduação tem possibilitado a discussão e fomento à pesquisa com interfaces transdisciplinares. Este tem procurado abordar a reflexão sobre os processos educativos interculturais que permitam visualizar outros modos de pensar as "infâncias". A partir das discussões da equipe do projeto, do conhecimento acumulado em pesquisas tendo os Guarani como principais interlocutores e da revisão bibliográfica efetuada, a seguir desenvolvemos algumas considerações sobre as relações de gênero em coletivos Guarani. Pois ao contemplar a educação das infâncias no plural priorizando a linguagem que busca recuperar a ação do corpo que a inscreve no mundo e lhe atribui sentido, identificamos a abertura do eixo analítico relacionado às relações de gênero no projeto, visto a necessidade de uma melhor compreensão deste tema nas práticas educativas interculturais que objetivam desenvolver metodologias que contemplem as especificidades dos saberes ameríndios.

Palavras chaves: relações de gênero, educação ameríndia, interculturalidade.

\section{Introdução}

O contato com os Guarani ${ }^{1}$ ao longo do tempo e em diferentes circunstâncias tem possibilitado compreender e se aproximar da visão do grupo no qual os sonhos fazem parte de uma dimensão poética, mitológica constituinte do ser que fala do que não pode ser controlado, de dimensões mediúnicas que colaboram no equilíbrio entre razão e sensibilidade, entre matéria e espírito, entre visível e invisível.

A vivência mediúnica dos sonhos é expressa nas falas de Dona Catarina, kunhã karai ${ }^{2}$, e da Martina, também integrante da aldeia, quando relatam que sonham com seus parentes

\footnotetext{
${ }^{1}$ As palavras em língua guarani não terão flexão conforme a língua portuguesa de número ou de gênero. O mesmo para etnônimos referentes aos povos indígenas, conforme a recomendação da maioria dos participantes da Primeira Reunião Brasileira de Antropologia, que ocorreu no Rio de Janeiro em 1953.

${ }^{2}$ Liderança espiritual da aldeia localizada no município de Estrela Velha- RS, uma das aldeias Guarani que temos contato através dos projetos desenvolvidos na Unisc.
} 
quando eles estão doentes. Segundo Dona Catarina, ela não precisa nem entrar em contato com os mesmos já que o sonho lhe traz a informação. Da mesma forma, Martina reitera a informação quando menciona os sonhos que tem com o seu pai e este com ela quando estão doentes.

Um dos desafios propostos na investigação que desenvolvemos ${ }^{3}$ é o de nos aproximar de um pensamento que seja seminal conforme proposto por Rodolfo Kusch (1977) quando busca mostrar a distinção entre um pensar causal ligado a inteligência (ciência=ocidental) e o pensar seminal que é relacionado com a afetividade (sentir=americano). O que nos remete do ponto de vista metodológico à possibilidade de adquirir e vivenciar uma visão orgânica da realidade por meio dos sentimentos. Pois por um lado a afetividade condiciona uma visão global de mundo e, por outro, a inteligência condiciona uma visão analítica do mesmo. Desta forma, a palavra- alma que no texto referimos nos conduz à dimensão da vivência com o sagrado tanto quanto a compreensão das relações de gênero presente nos mitos e nas práticas xamânicas. Ambas nos reportam ao pensamento seminal (KUSCH, 1977).

A seguir tecemos algumas considerações realizadas a partir da experiência com os Guarani e de uma revisão prévia da literatura sobre o tema. O objetivo é aprofundar os estudos em torno de processos de aprendizagens interculturais que considerem a inseparabilidade entre corpo, linguagem e mundo nos processos graduais de aprender a coexistir (MENEZES, 2006; MENEZES 2013; MENEZES, RICHTER, 2014).

As reflexões e autores aqui referidos são fontes de consulta e inspiração nas intenções que nos movem no percurso da pesquisa. O objetivo das linhas que seguem é sistematizar e promover aproximações teóricas que sinalizem as possibilidades holísticas de compreensão do pensamento mitológico dos coletivos ameríndios Guarani e de suas relações de gênero.

\section{Aproximações: a palavra e o modo de ser Guarani}

O encontro com a cosmologia Guarani a partir das crianças tem se revelado como encontro com a palavra antiga que os Guarani não esquecem, pois diz respeito ao sentido da casa, da morada de nossos saberes (MENEZES, RICHTER, 2014). A Opy ${ }^{4}$ como um dos espaços de aprendizagem dos Guarani e a aldeia como lugar de educação coletiva, apontam tanto para valores educacionais sustentados em uma ética enraizadas no "estar sendo" da

\footnotetext{
${ }^{3}$ Aprendizagens Interculturais com os Guarani: produção de conhecimentos ameríndios para a educação. Projeto de pesquisa (Unisc/Cnpq) coordenado por Ana Luisa Teixeira de Menezes (Unisc).

${ }^{4}$ Local sagrado de cerimônias e rezas nas aldeias.
} 
filosofia ameríndia de Kusch (1978), em um pensamento que mescla a cotidianidade com o misterioso e o transcendente.

A compreensão de interculturalidade como diálogo entre interlocutores no qual as práticas culturais cotidianas de vivências na aldeia nos diferentes espaços de aprendizagem aliados às cosmologias - encarnados em cada um é dada a partir da distinção estabelecida por Kusch (1978, p. 136) entre "o cultural" como processo e "a cultura" como institucionalização. Ao destacar os processos culturais como parte de dinâmicas existenciais, o autor os concebe como "o baluarte simbólico no qual cada um se refugia para defender a significação de sua existência" (KUSCH, 1978, p. 14).

Isto pressupõe ultrapassar uma concepção de cultura como "acervo espiritual" ou "totalidade" que determinado grupo oferece a cada um como tradição, Kusch (1978, p. 14). O autor propõe a substituição de uma perspectiva compartimentada ou dividida do humano, de forma a compreender os processos de aprendizagem em seu valor de ato, ou seja, não pelo que representam, mas pelo "estar sendo", como fluxo intercultural, tão profundo e misturado, por isso torna-se invisível à nossa visão de conhecimento.

As pesquisas já realizadas com os Guarani indicam que não existe a categoria do ensino e sim a do aprender. Uma aprendizagem que para Menezes (2006), em seus estudos sobre a dança Guarani, é relatada na gestualidade das crianças e na espontaneidade de movimentos que emergem da curiosidade, da atenção ao desejo de saber e participar do mundo. Aprendizagem está diretamente ligada a uma estética pautada na atenção à escuta do mundo, à manifestação da palavra sagrada, à espiritualidade e à corporeidade.

Desde os estudos da dança Guarani (MENEZES, 2006) aos trabalhos que abordam a dimensão poética da linguagem na educação das crianças (RICHTER, 2005; 2015), encontramos ênfase à compreensão da educação das crianças como iniciação à palavra poética que nos situa no mundo e que, na linguagem dos Guarani, torna-se palavra sagrada que os enraíza no mundo. Bartomeu Meliá, conhecedor da etnolinguística e da cultura Guarani assim se refere à palavra:

Para los guaraníes la palabra lo es todo y todo es palabra. Dios es dios em cuanto se abre a sí mismo como palabra; y de ahí, de la palabra a palabra, nace el amor, y el himno como "teoria" de palabras juntadas por el amor. Hay que escuchar algunos de esos cantos para dejarse impregnar por su autenticidade. Como los grandes místicos, los chamanes guaraníes está poseídos por la palabra inspirada que se hace cuerpo em el canto e la danza. La palabra se hace escuchar em la plegaria doméstica, lo mesmo que em los pequenos y grandes rezos cerimoniales. Son vários los encenarios y las ocasiones, desde la iniciación de los muchachos a las fiestas anuales del maíz (MELIÁ: 2006, p.202). 
Educar, para os Guarani, significa garantir o crescimento da palavra-alma, principalmente no primeiro ano de vida e que vai sendo cultivado ao longo da existência, a partir da compreensão do ñande reko, que significa modo de ser guarani. A palavra-alma como princípio remete para o conhecimento intuitivo o qual necessita ser compreendido.

A partir da experiência com as crianças passamos a nos perguntar sobre as articulações do aprender, das palavras, da palavra-alma com as relações de gênero, ou seja: dos saberes, das capacidades específicas relacionadas ao gênero, das atribuições, dos espaços de atuação e também da configuração do masculino e do feminino.

Percebemos que analisar o tema gênero em interface com a infância ou nas infâncias talvez seja possível ampliar a compreensão dos processos interculturais com a sociedade nacional, especialmente, no que se refere aos processos educativos direcionados aos coletivos ameríndios. Pois mesmo reconhecendo a centralidade do tema em terras baixas sulamericanas, MacCallum (2010) afirma que conhecemos muito pouco sobre o tema no âmbito da educação escolar indígena. Isto implica destacar que muitas das concepções de gênero relacionadas aos comportamentos dos coletivos ameríndios (das mulheres/meninas em especial) são percebidas como um atributo inato (da ordem da natureza), visto que inato é associado à natureza, portanto, exterior a ação humana.

Tais concepções usuais do senso-comum desconhecem a discussão acadêmica percursora dos estudos de gênero na perspectiva de construção social ${ }^{5}$ no âmbito das ciências comportamentais e sociais do final da década de cinquenta e de boa parte dos anos sessenta que propõem a compreensão de gênero em oposição a noção de sexo biológico, sendo que as definições do binômio masculino/feminino ocorreriam independente do sexo biológico ${ }^{6}$.

Em relação aos coletivos ameríndios é necessário lembrar não somente a crítica no âmbito das ciências sociais ao binarismo de gênero e ao fato deste reforçar a divisão natureza e cultura do ponto de vista hierarquizante ocidental, mas a ausência de problematizações sobre a transposição nas pesquisas com estes grupos de conceitos analíticos euro-centrados. Por isto objetivamos problematizar e relativizar as conceituações de gênero visando à compreensão das percepções dos grupos estudados que sinalizem as diferenças.

\footnotetext{
${ }^{5}$ Jonh Money (Psicólogo/sexologista) considerado pioneiro nos estudos de gênero ao questionar o determinismo biológico e enfatizar que os papéis de gênero são construídos socialmente.

${ }^{6}$ Argumenta-se que os papéis de gênero são inteiramente arbitrários e que a biologia não interfere nos comportamentos sociais. Atualmente, parte das conceituações contemporâneas das Ciências Sociais refere-se às identidades de gênero. No que diz respeito ao masculino e feminino como: masculinidades e feminilidades no plural ao invés do singular enfatizando a diversidade tanto dentro das culturas como entre as mesmas. A este respeito ver: HEILBORN, M.L. e ZAMBRANO, E. In: Identidade de gênero. In: LIMA, Antônio Carlos de Souza (Coord.). Antropologia \& direito: temas antropológicos para estudos jurídicos. Rio de Janeiro: ABA, 2012.
} 
Considerando a premissa mencionada acima, um dos eixos analíticos da investigação que iniciamos e que compõe a pesquisa referida prevê a coleta e análise das narrativas de mulheres xamãs (as Kunhã $\mathrm{Karai}^{7}$ ) no que diz respeito às práticas curativas, aos rituais relacionados ao corpo e a transmissão de conhecimentos. Dona Catarina, referida anteriormente, é uma das lideranças espirituais que nos inspira a conhecer e nos transporta a complexidade do pensamento ameríndio que desafia nosso entendimento para além das dualidades ontológicas, entre elas a do dualismo natureza versus cultura.

E, em parte da revisão bibliográfica realizada a tensão da discussão clássica da antropologia sobre o dualismo natureza e cultura se faz presente de forma a reafirmar unidade da constituição humana e destacar a importância do regramento social para constituição da cultura. Tema abordado na Antropologia Cultural norte-americana de Franz Boas no início do século XX e posteriormente na obra de Claude Lévi-Strauss (1976) ${ }^{8}$ e de Marcel Mauss, onde o corpo e suas representações sociais oferecem uma das vias de acesso à estrutura de uma sociedade (MAUSS,1974).

Entretanto, ao observar que o estudo das relações de gênero e das cosmologias, associados aos significados do corpo, nos coletivos Guarani reatualizam a reflexão sobre natureza versus cultura, nos aproximamos da teoria do perspectivismo ameríndio e da obra de Rodolfo Kusch. As quais buscam transpor este dualismo o que nos parece ser fundamental para a compreensão do modo de ser guarani (ñande reko).

\section{Aproximações: corpo e gênero}

Atualmente, a maioria dos estudos etnológicos sobre xamanismo situados nas terras baixas da América do Sul apontam a importância e centralidade da discussão do dualismo natureza e cultura e o trânsito pela teoria do perspectivismo ameríndio, desenvolvida por Eduardo Viveiros de Castro (2004) que problematiza esta dualidade defendendo a ideia de que a humanidade é uma questão de perspectiva (VIVEIROS DE CASTRO, 2004, p.227230).

Para o autor, o mundo é habitado por diferentes espécies de sujeitos e pessoas, humanos e não humanos que o apreendem (assimilam/captam) segundo pontos de vistas

\footnotetext{
${ }^{7}$ Projeto de pesquisa de Doutorado desenvolvido no Programa de Antropologia da Universidade Federal de Pelotas (Ufpel), de Josiane A. S. Ulrich, professora da Universidade de Santa Cruz do Sul (Unisc).

${ }^{8}$ Lévi-Strauss (1976) mostra a importância da existência do tabu do incesto, como uma regra comum em todos os agrupamentos humanos que sinaliza a passagem da natureza a cultura. A partir disto, podemos dizer que a antropologia cultural do século XX procurou demostrar que o comportamento humano é fruto de regramentos culturais e não de determinações inatas.
} 
distintos. O que significa perceber as relações entre humanos e não humanos a partir de um campo relacional onde a natureza passa a ser concebida entre diferentes perspectivas provocando a superação de modelos explicativos dicotômicos (naturalistas ou culturalistas) pela compreensão das relações entre sociedade e natureza (VIVEIROS DE CASTRO, 2004), o que pode ser constatado, particularmente, nos estudos do xamanismo na Amazônia ${ }^{9}$. Isto possibilita a abertura de um campo investigativo desafiador. Se esta teoria teve sua origem na etnografia Tupi, talvez ela possa ser percebida em terras baixas da América do Sul como um todo (SZTUTMAN, 2009).

As perspectivas mais recentes em consonância com o perspectivismo e as leituras efetuadas sugestionadas pela teoria acima, entre outras, indicam importância da categoria corpo em estudos que abordam os coletivos ameríndios. Muitas das quais buscam analisar as interações das cosmologias ameríndias nas relações sociais em diferentes domínios evitando a dualidade entre natureza e cultura através da ideia de interação entre os diversos domínios (humanos e não humanos), percebidos como parte de uma totalidade (CREPEAU, 1997; 1998).

Tal perspectiva é relativamente recente, pois na literatura sobre os Guarani, de forma geral, praticamente não encontrarmos menção às relações de gênero, às mulheres e ao significado de suas relações com a cosmologia, principalmente nas obras mais clássicas e as sistematizações da mesma, ${ }^{10}$ pois enfatizam a análise das migrações (mobilidade), do profetismo e religiosidade que são contribuições inigualáveis para a etnologia americana constantemente revisitadas ao tratarem da mobilidade ${ }^{11}$ territorial dos Guarani (CLASTRES, 1978; SHADEN, 1962).

Exemplo disto pode ser observado no trabalho de referência de Hélène Clastres (1978) quando aborda no segundo capítulo de seu reconhecido livro ${ }^{12}$, o tema dos pajés e caraíbas e a hierarquia dos xamãs a partir da revisão da literatura. Isto não significa necessariamente a

\footnotetext{
9 "O xamanismo amazônico pode ser definido como a habilidade manifesta por certos indivíduos de cruzar deliberadamente as barreiras corporais e adotar a perspectiva de subjetividades alo-específica, de modo a administrar as relações entre estas e os humanos. Vendo os seres não humanos como estes se veem (como humanos), os xamãs são capazes de assumir o papel de interlocutores ativos no diálogo transespecífico; sobretudo, eles são capazes de voltar para contar a história, algo que os leigos dificilmente podem fazer." (VIVEIROS DE CASTRO: 2004 p.231)

${ }^{10}$ Bibliografia Etnológica Básica Tupi-Guarani. In: Revista de Antropologia, n. 27, SP: 1984; MELIÁ, Bartomeu. O Guarani - Uma bibliografia etnológica. Santo Ângelo: Fundames, 1987.

${ }^{11}$ A busca da Terra sem mal é um dos instigantes aspectos da cultura Guarani. Existem muitas abordagens sobre o tema e as explicações dadas às migrações proféticas dos Guaranis. De forma a exemplificar uma das possíveis interpretações referimos que: A Terra sem mal é um lugar a ser buscado na vida o que explicaria em parte a necessidade de migrar ou caminhar (CLASTRES, 1978).

${ }^{12}$ CLASTRES, Hèléne. Terra sem mal: o profetismo Tupi-Guarani. SP: Brasiliense, 1978.
} 
ausência de um olhar investigativo para tais relações, mas possivelmente retrate o panorama histórico das obras.

Já nas últimas décadas são confeccionadas novas produções acadêmicas sobre os Guarani tanto no Sudeste como no Sul do Brasil. Relevando as especificidades de abordagens analíticas é possível, por exemplo, encontrar confluências entre os trabalhos de Elizabeth Pissolato (2007) e de Maria Paula Prates (2009). Ambas autoras desenvolvem uma densa discussão sobre a construção da pessoa Mbyá-Guarani ${ }^{13}$ aliada à análise das práticas cotidianas encontradas nas aldeias em que realizaram suas pesquisas. No caso da primeira autora existe uma articulação entre a compreensão da mobilidade Guarani ao parentesco e a cosmologia no tratamento de questões como a concepção e a nominação. Quando analisa os cuidados pós- nascimentos identifica que para os Guarani não cabe a dicotomia entre corpo e alma (PISSOLATO, 2007, p. 282-283).

A composição da tríade corpo, pessoa e, segundo Maria Paula Prates (2009), aguyje (condição de perfeição), são fundamentais para a compreensão das relações dos Guarani com o cosmo. O entendimento do corpo decorre da necessidade de intervenções contínuas sobrepujando a dualidade corpo e alma na medida em que para a autora, corpo-pessoa são indissociáveis (PRATES, 2009). Em sua dissertação de mestrado dedica um capítulo às relações de gênero através da análise do mito de criação Mbya-Guarani e se detém na relação corpo-pessoa quando analisa os significados do sangue menstrual e a concepção na fabricação do corpo (PRATES, 2009, p.81).

De outra forma, Mariana de Andrade Soares (2013), através de uma breve descrição de atividades cotidianas no interior da aldeia em que pesquisou no Estado do Rio Grande do Sul, identifica nas narrativas das mulheres, a importância em guardar o segredo das plantas, as narrativas sobre a origem das mulheres, assim como a importância do corpo, enquanto categoria no universo feminino estudado (SOARES, 2013, p.63-64). Referencias que também são encontradas na dissertação de mestrado de Lauriene Seraguza (2013) quando analisa a fabricação do corpo e as relações com as cosmologias sob a ótica das mulheres Kaiowa e Guarani em Mato Grosso do Sul.

Cabe ressaltar o trabalho de Celeste Ciccarone (2004), um dos poucos- se tratando de estudos sobre os Guarani- em que uma mulher xamã ganha destaque. A autora analisa o movimento migratório e a liderança de Tatati yva Rete, proveniente do Paraguai, que por

\footnotetext{
${ }^{13}$ A noção de pessoa utilizada na bibliografia referida parte da conceituação referida por Eduardo Viveiros de Castro (1979) onde ele percebe que o corpo forma a pessoa. A análise da corporeidade definida a partir da compreensão simbólica do corpo passa a ser fundamental para o entendimento das cosmologias e a organização social nas sociedades ameríndias.
} 
meio século migrou continuamente rumo ao litoral norte do Espírito Santo (CICCARONE, 2004, p. 84).

Ao que parece a possibilidade de entender as relações de gênero entre os coletivos ameríndios aqui priorizados passa pela análise da corporeidade aliada à compreensão do xamanismo. Uma das vias de acesso a apreensão dos significados e das distinções de gênero nos coletivos ameríndios, na investigação em curso, tem sido a compreensão do corpo/corporeidade conjuntamente com os mitos a partir do acesso a cosmologia Guarani.

$\mathrm{Na}$ etnologia indígena contemporânea, a "corporeidade" é entendida como um dos mecanismos centrais do processo de aprendizagem e transmissão de conhecimentos sendo está constituinte de um "modo de ser guarani" ligado aos sonhos e aos mitos. Os processos de identidade e de subjetividade relacionados ao corpo, gênero e as relações interculturais nos espaços de aprendizagem na cultura dos Guaranis, como em outras etnias, são expressivos para a compreensão das cosmologias indígenas.

\section{Considerações finais}

O esforço acadêmico levado adiante pela equipe do projeto tem sido o de integrar na pesquisa educacional os aspectos teóricos e vivenciais e, portanto, também metodológicos. Por intermédio da reflexão da linguagem tomando a palavra-alma como um princípio significativo, conforme referido, que poderá redimensionar as percepções analíticas do corpo e das relações de gênero, buscamos acessar algumas das possibilidades de relações transdisciplinares com o campo educativo. A reflexão sobre as configurações ou reconfigurações do masculino e do feminino (binarismo de gênero) contribuem para uma melhor operacionalização de políticas públicas, educacionais em especial, direcionadas aos Guarani nas relações interculturais com a sociedade nacional.

Identificamos na pesquisa em curso a necessária e urgente relativização dos parâmetros norteadores de construção do binarismo de gênero e saberes sobre o corpo que são valorizados no senso comum e reproduzidos nas relações com os Guarani. Nos perguntamos: quais as limitações e tensões nas transposições efetuadas do conceito de gênero para a análise das relações de gênero em sociedades ameríndias? Observamos que é necessário romper com a dualidade natureza e cultura para compreender a percepção do modo de ser Guarani. Destacamos que a obra de Rodolfo Kusch e o perspectivismo ameríndio têm se mostrado atual. São fontes de inspiração no nosso horizonte da pesquisa, possibilitando as aproximações reflexivas que começamos a trilhar. 
Por fim, percebemos a necessidade de aprofundar esta discussão ao longo da pesquisa, considerando que as possibilidades de compreensão das relações de gênero entre os coletivos Guarani perpassam os múltiplos significados da corporeidade que nos possibilita acessar o modo de ser guarani.

\title{
INTERFACES BETWEEN THE PRODUCTION OF AMERINDIAN KNOWLEDGE AND GENDER RELATIONS WITH THE GUARANI PEOPLE
}

\begin{abstract}
The project "Intercultural learning with the Guarani people and production of Amerindian knowledge for education", developed by the University of Santa Cruz do Sul (Unisc), which brings together professors, graduate and undergraduate students has enabled the discussion and fostered the research with transdisciplinary interfaces. It has sought to address the reflection on the intercultural educational processes that allow to visualize other ways of thinking the "childhood". Based on the discussions of the project team, the accumulated knowledge in surveys having the Guarani people as main interlocutors and the bibliographical review carried out, we have developed some considerations about the gender relations in the Guarani groups. When contemplating the education of childhood in the plural, prioritizing the language that seeks to recover the action of the body that inscribes it in the world and gives it meaning, we identify identified the opening of the analytical axis related to the gender relations in the project since the need for a better understanding of this theme in intercultural educational practices that aim to develop methodologies that contemplate the specificities of Amerindian knowledge.
\end{abstract}

Keywords: gender relations, amerindian education, interculturality.

\section{INTERFACES ENTRE LA PRODUCCIÓN DE CONOCIMIENTOS AMERINDIOS Y LAS RELACIONES DE GENERO CON LOS GUARANÍ}

\section{Resumen}

El proyecto "Aprendizajes interculturales con los Guaranís y producción de conocimientos amerindios para la educación", desarrollado por la Universidade de Santa Cruz do Sul (Unisc) que reúne profesores, estudiantes de posgrado y graduación tiene posibilitado la discusión y fomento a la investigación con interfaces transdisciplinarias. Este tiene buscado abordar la reflexión sobre los procesos educativos interculturales que les permitan mirar y reflexionar otros modos de pensar las "infancias". Desde las discusiones del equipo del proyecto, del conocimiento de las investigaciones que tiene los guaranís como principales interlocutores y de la revisión bibliográfica realizada, desarrollamos algunas consideraciones a respecto de las relaciones de género en colectivos guaranís. Puesto que contempla la educación de las infancias en el plural privilegiándose el lenguaje que busca recuperar la acción del cuerpo que le inscribe en el mundo y le asigna sentido, identificamos la apertura del eje analítico relacionado a las relaciones de género en el proyecto, a la necesidad de una mejor comprensión del tema en las prácticas educativas interculturales que objetivan desarrollar metodologías que tengan las especificidades de los saberes amerindios.

Palabras-clave: relaciones de género, educación amerindia, interculturalidad. 


\section{Referências}

CLASTRES, Helene. Terra sem mal: o profetismo Tupi-Guarani. SP: Brasiliense, 1978.

CICCARONE, Celeste. Drama e sensibilidade: migração, xamanismo e mulheres mbya. Revista de índias, v. LXIV, n. 230, p. 81-96, 2004.

LÉVI-STRAUSS, Claude. As estruturas elementares do parentesco. Petrópolis: Vozes, 1976. $537 \mathrm{p}$

CRÉPEAU, Robert R. (Org.). Recherches Amérindiennes au Québec, Montréal, v. 18, n. $2-3,1988$

Le chamane croit-il vraiment à sés manipulations et à leurs fondements intellectuels? Recherches Amérindiennes au Québec, Montréal, v. 27, n. 3-4, p. 7-17,1997.

KUSCH, Rodolfo. El pensamiento indígena y popular en América. Hachette. Buenos Aires. 1977

KUSCH, Rodolfo. Esbozo de una antropologia filosofica americana. Buenos Aires: Ediciones Castañeda, 1978.

KUSCH, Rodolfo. America Profunda. Buenos Aires: Editorial BONUM, 1986.

MAUSS, Marcel; LÉVI-STRAUSS, Claude; ALMEIDA, Mauro Barbosa de. Sociologia e antropologia. São Paulo: EDUSP, 1974.

McCALLUM, Cecília. Escrito no corpo: gênero, educação e socialidade na Amazônia numa perspectiva Kaxinawá. Revista da FAEEBA: Educação e Contemporaneidade. v. 19, n. 33, p. 87-104, jan. /jun. 2010.

MELIÁ, Bartomeu. Mitología Guarani. In: RESCANIERE,Alejandro Ortiz. Mitologias Amerindias. Madri: Editoral Trotta, 2006, p.177-209.

MENEZES, Ana Luisa. Teixeira de. A alegria do corpo-espírito saudável: ritos de aprendizagem guarani. Tese (Doutorado em Educação) - PPGEdu/UFRGS, Porto Alegre, RS, 2006.

educação mitológica Guarani na indissociabilidade ensino, pesquisa e extensão. In M. Dimenstein \& J.F. Leite (Orgs), Psicologia e contextos rurais. Natal, RN :EDUFRN, 2013.

MENEZES, Ana Luisa Teixeira de; RICHTER, Sandra R. S. Infância e educação Guarani: para não esquecer a palavra. Revista TELLUS, n 26. 2014.

PISSOLATO, Elizabeth. A Duração da Pessoa - mobilidade, parentesco e xamanismo Mbya (Guarani). São Paulo: Editora Unesp/ISA, Rio de Janeiro: Nuti, 2007. 
PRATES, Maria Paula. Dualidade, pessoa e transformação: relações sociocosmológicas Mbyá-Guarani de três aldeias no RS. Dissertação (Mestrado em Antropologia Social), Porto Alegre: PPGAS, UFRGS, 2009.

RICHTER, Sandra R.S; BERLE, S. Pedagogia como gesto poético de linguagem. Educação e Realidade, v. 40, p. 1027-1043, 2015.

RICHTER, Sandra R.S. O sensível sob o admirar filosófico. Educação \& Realidade, Porto Alegre: Universidade Federal do Rio Grande do Sul/Faculdade de Educação, v. 30, n. 2, p. 187-202, jul./dez. 2005.

SERAGUZA, Lauriene. Cosmo, corpos e mulheres Kaiowa e guarani de Anã a Kunã. Dissertação (Mestrado em Antropologia Sociocultural). Mato Grosso do Sul: PPGA, UFGD, 2013.

SHADEN, Egon. Aspectos Fundantes da Cultura Guarani. SP: Difusão Europeia do Livro, 1962.

SOARES, Mariana de Andrade. Caminhos para viver o Mbya Reko: estudo antropológico do contato interétnico e de políticas públicas de etonodesenvolvimento a partir de pesquisa etnográfica junto a coletivos guarani no Rio grande do Sul. Tese (Doutorado em Antropologia Social), Porto Alegre: PPGAS, UFRGS, 2013.

VIVEIROS DE CASTRO, Eduardo. Perspectivismo e multinaturalismo na América indígena. In: O que nos faz pensar. Cadernos do Departamento de Filosofia da Puc-Rio.n.18, set.2004.

SZTUMAN, Renato. Natureza \& Cultura, versão americanista - Um sobrevoo. Ponto Urbe [online], $4 \mid 2009$, posto online no dia 31 julho 2009, consultado em 13 de fevereiro 2016. URL: http://pontourbe.revues.org/1468; DOI: 10.4000/pontourbe.

Data de recebimento: 20/01/2017

Data de aceite: 14/06/2017

\section{Sobre as autoras:}

Josiane Abrunhosa da Silva Ulrich é Doutoranda no Programa de Pós-Graduação em Antropologia da Universidade Federal de Pelotas-RS. Mestre em Antropologia Social pela Universidade Federal do Rio Grande do Sul. É professora do Departamento de Ciências Humanas da Universidade de Santa Cruz do Sul (UNISC), participa como pesquisadora da equipe do projeto de Pesquisa: Aprendizagens Interculturais com os Guarani: produção de conhecimentos ameríndios para a educação- (UNISC/Cnpq/Brasil). Endereço Eletrônico: josiane@unisc.br

Ana Luisa Teixeira Menezes é Doutora em Educação pela Universidade Federal do Rio Grande do Sul. É professora titular do departamento de psicologia e professora permanente do Mestrado em Educação da UNISC. Coordena o projeto de pesquisa: Aprendizagens Interculturais com os Guarani: produção de conhecimentos ameríndios para a educação. (UNISC/Cnpq/Brasil). Integra o projeto Abya Yala Epistemologias em rede e é vice coordenadora do GT de Saúde Comunitária da ANPEPP. Endereço Eletrônico: luisa@unisc.br 